\title{
Cosegregation of Robertsonian metacentric chromosomes in the first meiotic division of multiple heterozygous male mice as revealed by FISH analysis of spermatocyte II metaphases
}

\author{
M. Scascitelli, a F. Pacchierotti, ${ }^{b}$ M. Rizzoni, ${ }^{a}$ B. Gustavino a and F. Spirito ${ }^{c}$ \\ a Department of Biology, University of Rome, "Tor Vergata"; \\ b Section of Toxicology and Biomedical Sciences, ENEA CR Casaccia; \\ c Department of Genetics and Molecular Biology “C. Darwin”, University of Rome "la Sapienza”, Rome (Italy)
}

\begin{abstract}
Contrasting results (random segregation or cosegregation of isomorphic chromosomes) have been reported up to now on the segregation pattern of Robertsonian metacentric chromosomes of Mus musculus domesticus in multiple heterozygotes, using different approaches (karyotypical analysis of the progeny or of second meiotic metaphases). In the present contribution data are presented based on FISH (Fluorescence In Situ Hybridisation) analysis with telomeric probes, which allowed us to distinguish metacentric chromosomes from pairs of acrocentric chromosomes with their centromeric regions close
\end{abstract}

to each other. Probes were hybridized to DAPI stained metaphases of spermatocytes II of mice heterozygous for two, three or four Robertsonian metacentrics in an all-acrocentric background, the karyotype of which has been reconstructed starting from laboratory strains. Isomorphic chromosomes tend to cosegregate (metacentrics with metacentrics, acrocentrics with acrocentrics); the values found for cosegregation have a clear even if moderate effect on the reproductive isolation caused by underdominant chromosomal rearrangements.

Copyright $@ 2003$ S. Karger AG, Basel
Many chromosomal races of Mus musculus domesticus in Europe and North Africa are differentiated by the fixation of Robertsonian $(\mathrm{Rb})$ chromosomes, arisen from the centric fusion of acrocentric chromosomes.

Recent analysis of the fertility of wild-caught and laboratory-reared hybrids, heterozygous for one or more $\mathrm{Rb}$ chromosomes, revealed a decrease of the fertility if compared to the parental homozygotes (see Searle, 1993 for a review; more

Supported by CNR, grant 99.02579.CT04. This work is a subject of the Ph.D. thesis of M. Scascitelli for the Evolutionary Biology and Ecology Ph.D. School, Dept. Biology, Univ. Roma "Tor Vergata".

Received 6 February 2003; manuscript accepted 20 May 2003.

Request reprints from Marco Rizzoni

Dip. Biologia, Univ. Roma "Tor Vergata"

via della Ricerca Scientifica s.n.c. Roma RM 00133 (Italy)

telephone: (0039-6) 72594812; fax: (0039-6) 2023500

e-mail:rizzoni@uniroma2.it

Current address of M.S.: Dip. Biologia, Univ. Roma "Tor Vergata”, via della Ricerca Scientifica s.n.c., 00133 Roma, RM, (Italy). recently, Hauffe and Searle, 1998; Castiglia and Capanna, 2000).

In a general context, heterozygote disadvantage is an essential condition for the reduction of gene exchange between chromosomally differentiated populations, acting as a postzygotic reproductive isolating mechanism. If this disadvantage is strong, fixation probability of newly arisen rearrangements is low and isolation efficiency is high; the reverse occurs if such a disadvantage is weak. The conditions required for "chromosomal speciation" (White, 1968, 1978), are a non-negligible fixation probability of newly arisen chromosomal rearrangements, a long-term persistence of the new chromosomal race, a good efficiency of chromosomal rearrangements as a barrier to gene exchange.

The occurrence of some other factors has been proposed for the accomplishment of the speciation process such as meiotic drive, genetic drift, inbreeding and selective advantage for the homozygous "new" rearrangement, including interactions among several chromosome rearrangements (Barton, 1979, 1983; Lande, 1979, 1984; Hedrick, 1981; Walsh, 1982; Barton and Bengtsson, 1986); such chromosomal rearrangements have \begin{tabular}{lll}
\hline KARGER & $\begin{array}{l}\text { Fax +41 61306 12 34 } \\
\text { E-mail karger@karger.ch } \\
\text { www.karger.com }\end{array}$ & ( 2003 S. Karger AG, Basel \\
$0301-0171 / 03 / 1012-0136 \$ 19.50 / 0$
\end{tabular}
Accessible online at: www. karger.com/cgr 
a non-negligible probability to be fixed, to persist and to reduce significantly the gene flow only in the presence of these factors, therefore it is essential to verify their existence and role to reconsider the question of "chromosomal speciation" (White, 1968, 1978).

In the present study, we analyse another factor, the non-random segregation of multiple heterozygous $\mathrm{Rb}$ chromosomes during the first meiotic division. In the presence of cosegregation metacentric chromosomes tend preferentially to comigrate to the same spindle pole and acrocentric ones do the same. The possible presence of cosegregation could affect both the structure of hybrid zones between chromosomal races and gene flow through them and, by this way, the entire speciation process.

Results of the karyotypical analysis of a backcross progeny from males heterozygous for three $\mathrm{Rb}$ metacentric chromosomes (White et al., 1978), although compatible with a random segregation, fit better with a $P$ value (see below) of preferential segregation of 0.66 (95\% confidence limits: 0.50-0.75) (Rizzoni and Spirito, 1999). Data derived from karyotypical analysis of embryos obtained by backcrossing heterozygotes for nine centric fusions (Said et al., 1993) show preferential segregation (0.66, $95 \%$ confidence limits 0.56-0.71) (Rizzoni and Spirito, 1999). The chromosomal analysis of backcross progeny from crosses between the two subspecies Mus musculus domesticus and $M . m$. musculus shows a random segregation of the three $\mathrm{Rb}$ fusions inherited from $M$. m. domesticus (Lenormand et al., 1997). A hypothesis of selective processes occurring during embryo development is suggested, in which competition between embryos carrying $\mathrm{Rb}$ metacentric or acrocentric chromosomes occurs at two stages of embryogenesis, pre- and postimplantation. Analysis of segregation pattern of trivalents in quadruple heterozygous males caught in a chromosomal hybrid zone, by cytogenetic analysis of spermatocytes II (Rizzoni and Spirito, 1999) show that Rb metacentrics do not segregate independently of each other, but tend to cosegregate with a probability value of segregation towards the preferential pole of 0.71 (95\% confidence limits: 0.62-0.77). Contrasting cosegregation data from the same hybrid zone (Castiglia and Capanna, 2000) have been recently obtained with evidence of random segregation for these chromosomes in studies of spermatocytes II, but also with some evidence of cosegregation after karyotype analysis of $F_{2}$ individuals.

Therefore metaphases of spermatocytes II of $F_{1}$ mice, heterozygous for two, three or four Robertsonian metacentrics in an all-acrocentric background were analysed using FISH techniques on DAPI stained metaphases. Telomeric probes were used to distinguish without ambiguity metacentric chromosomes from pairs of acrocentric chromosomes with their centromeric regions close to each other. Male $F_{1}$ mice, heterozygous for two, three or four Robertsonian metacentrics in an allacrocentric background, were obtained by crossing specimens from homozygous laboratory strains in the ways described below.

Segregation patterns of trivalents during the first meiotic division were analysed. The effects of nonrandom segregation on the stability of a population with $\mathrm{Rb}$ chromosomes and on the gene flow between it and a population with the standard karyotype were evaluated.

\section{Materials and methods}

\section{Karyotypes and strains}

Heterozygous karyotypes were reconstructed as follows:

$\mathrm{F}_{1}$ heterozygous males for two $\mathrm{Rb}$ metacentric chromosomes $(\mathrm{Rb}$ [1.3]1Bnr, $\mathrm{Rb}$ [9.14]6Bnr) were obtained mating all-acrocentric $\mathrm{C} 57 \mathrm{Bl} /$ B6 females (Harlan, Italy) with Rb16Bnr/Ei males, homozygous for the two $\mathrm{Rb}$ metacentric chromosomes (The Jackson Laboratory, Bar Harbor, Maine, USA).

$\mathrm{F}_{1}$ heterozygous males for three $\mathrm{Rb}$ metacentric chromosomes ( $\mathrm{Rb}[1.3] 1 \mathrm{Bnr}, \mathrm{Rb}$ [4.6]2Bnr, $\mathrm{Rb}$ [9.14]6Bnr) were obtained mating all-acrocentric C57Bl/B6 females (Harlan, Italy) with Rb126Bnr/Ei males, homozygous for the three $\mathrm{Rb}$ metacentric chromosomes (The Jackson Laboratory, Bar Harbor, Maine, USA).

$F_{1}$ heterozygous males for four $\mathrm{Rb}$ metacentric chromosomes (Rb[1.3]1Bnr, Rb[4.6]2Bnr, Rb[9.14]6Bnr, Rb[16.17]7Bnr) were obtained mating Rb7Bnr homozygous females carriers of the metacentric chromosome Rb(16.17)7Bnr (The Jackson Laboratory, Bar Harbor, Maine, USA) with Rb126Bnr/Ei males, homozygous for the other three Rb metacentric chromosomes (The Jackson Laboratory, Bar Harbor, Maine, USA).

\section{Slide preparation and analysis}

Specimens were killed by cervical dislocation when they were ten weeks old; six double heterozygous males, four triple heterozygous males and three quadruple heterozygous males were studied. Slides were prepared following Evans' air-drying method (Evans et al., 1964). Metaphases of spermatocytes II were hybridised with a human pan-telomeric $\mathrm{Cy}-3$ conjugated DNA probe (Cambio, Cambridge, UK) according to the company recommended protocol, to label telomeres of DAPI counterstained chromosomes. Slides were dehydrated (1 min in 70, 90 and $100 \%$ ethanol) and denatured (70\% formamide in $2 \times \mathrm{SSC}, 2 \mathrm{~min}$ at $65^{\circ} \mathrm{C}$ ). The probes, pre-warmed at $37^{\circ} \mathrm{C}$ for $5 \mathrm{~min}$, were denatured at $85^{\circ} \mathrm{C}$ for $15 \mathrm{~min}$, then placed on ice. Hybridisation was performed overnight at $37^{\circ} \mathrm{C}$ in a moist chamber. Post-hybridisation washing consisted of two washes $\left(0.1 \%\right.$ Tween $20,0.2 \times \mathrm{SSC}, 2$ min at $37^{\circ} \mathrm{C}$; $0.1 \%$ Tween $20,1 \times \mathrm{SSC}, 1 \mathrm{~min}$ at RT). Slides were counterstained with DAPI in antifade $(0.2 \mu \mathrm{g} / \mathrm{ml})$. Single propidium iodide and DAPI filters were used in an AX70 Olympus microscope; images, collected by a monochromatic Cohu CCD camera, were elaborated with IAS 2000 software. For each specimen observation was performed until 50 haploid (euploid) spermatocytes II were analysed; all the aneuploid hyperploid metaphases found during the observation were also analysed. Hypoploid cells were not scored as they may be due to artifactual chromosome loss. Each metaphase II plate was classified for the number of chromosome arms and metacentric chromosomes (Fig. 1a and b); plates with less than $95 \%$ labelling efficiency (i.e. with more than four unequivocal telomeres unlabelled) were excluded from the observation. This threshold makes very unlikely mistakes in classifying chromosomes as pairs of acrocentrics or as metacentric. The only possible mistake, indeed, is the contemporary lack of label of the four telomeres close to the centromeres of two acrocentrics with their centromere regions close to each other.

Then each metaphase II plate analysed was attributed its own segregation pattern of Rb metacentric chromosomes, defined by the number of Rb metacentric chromosomes migrated to each pole of the first meiotic division from which it originated: to describe the segregation patterns of several heterozygous $\mathrm{Rb}$ rearrangements, $(\mathrm{i}, \mathrm{n}-\mathrm{i})$ indicates the segregation pattern of meiosis I involving $\mathrm{n}$ trivalents in which $\mathrm{i} \mathrm{Rb}$ metacentrics segregate to one pole and the remaining $\mathrm{n}-\mathrm{i}$ to the other pole; e.g., for double heterozygotes there are two possible segregation patterns: $(2,0)$, if both metacentric chromosomes migrate to the same pole; $(1,1)$ if they migrate to the opposite poles. The relative frequency of such segregation patterns is denoted by $f(i, n-i)$, the absolute frequency by $\mathrm{F}(\mathrm{i}, \mathrm{n}-\mathrm{i})$.

The frequencies of the different segregation patterns were evaluated for each specimen; furthermore, after passing a $\chi^{2}$ homogeneity test (see Tables $2 \mathrm{a}, \mathrm{b}, \mathrm{c})$, segregation data of $\mathrm{Rb}$ metacentrics from different specimens with the same karyotype were also pooled.

\section{Analysis of data}

Cosegregation coefficient (c) was used as a measure of the tendency of isomorphic chromosomes (chromosomes with the same "shape", i.e. metacentric or acrocentric) to segregate together to the same meiosis I pole; $\mathrm{c}$ consists of the probability to reach the same pole for any pair of isomorphic 


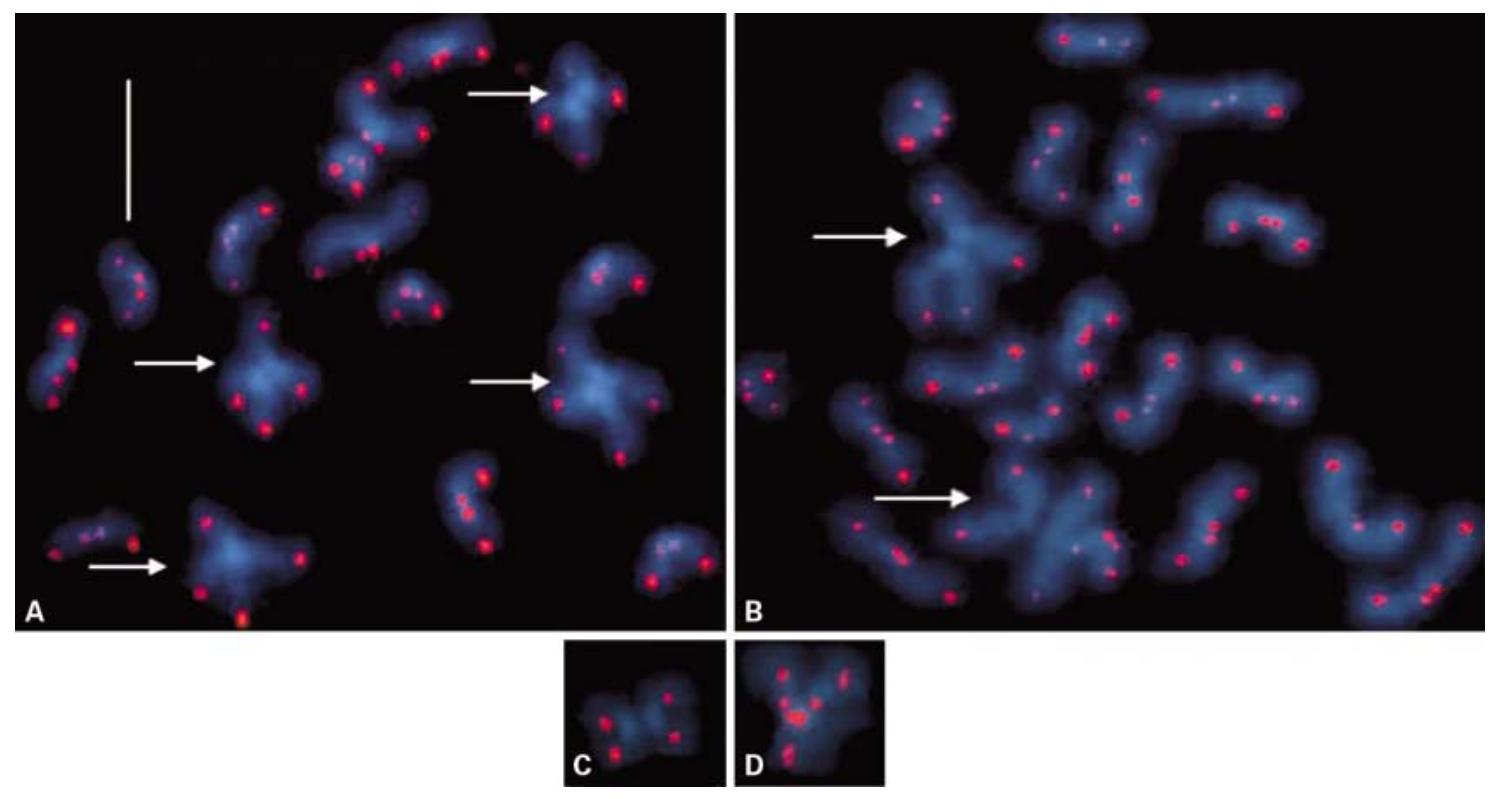

Fig. 1. Telomeric probe signals in DAPI stained chromosomes of mouse spermatocyte II metaphases; arrows point to Rb metacentric chromosomes; vertical yellow bar represents $10 \mu \mathrm{m}$. (A) Euploid metaphase plate ( 20 chromosome arms) with four metacentric chromosomes from a specimen heterozygous for four Rb metacentric chromosomes; (B) aneuploid metaphase plate, presumably double disomic, (22 chromosome arms) with two metacentric chromosomes from a specimen heterozygous for three $\mathrm{Rb}$ metacentric chromosomes; (C) an Rb metacentric chromosome; (D) a pair of acrocentric chromosomes with centromeric regions close to each other; in the absence of telomere labeling, such an image could have been misinterpreted as a metacentric chromosome.

chromosomes; in turn, we denote as $P$ the probability, for any chromosome with a given shape (e.g. metacentric) to migrate to its "preferential" meiosis I pole, which is the same for all the isomorphic chromosomes. This variable has been reported in literature as a measure of cosegregation (Rizzoni and Spirito, 1999). Preferential migration could be due to a co-orientation of the centromeres of the isomorphic chromosomes when spindle is organised; by this way they may interact with a high probability with the same spindle pole.

The values of $\mathrm{c}$ were estimated by experimental data as follows: $\mathrm{c}$ was calculated directly in the heterozygotes for two Rb metacentrics as the proportion of meiosis I with the $(2,0)$ segregation pattern, i.e. $\mathrm{f}(2,0)$; $\mathrm{c}$ was calculated in the heterozygotes for three Rb metacentrics, assuming the same values of $\mathrm{c}$ for any pair of metacentrics; the maximum likelihood estimate of $\mathrm{c}$, is $\mathrm{f}(3,0)+\mathrm{f}(2,1) / 3$ (see Appendix, 1a);

$\mathrm{c}$ was calculated in the heterozygotes for four Rb metacentrics, assuming the same values of $\mathrm{c}$ for any pair of metacentrics. By simple computations, it results: $f(2,2)=3 / 2(1-c)^{2}, f(3,1)=2 c(1-c), f(4,0)=1 / 2 c^{2}+c-1 / 2$ (see Appendix, 1b). Therefore, using the maximum likelihood method, the logarithm of the likelihood function is the following:

$$
\log (\mathrm{L})=\mathrm{F}(4,0) \log \left(1 / 2 \mathrm{c}^{2}+\mathrm{c}-1 / 2\right)+\mathrm{F}(3,1) \log \left(2 \mathrm{c}-2 \mathrm{c}^{2}\right)+
$$$$
F(2,2) \log \left(3 / 2 c^{2}-3 c+3 / 2\right) \text {; }
$$

the maximum likelihood estimate is the value of $\mathrm{c}$ which gives the highest value of $\log (\mathrm{L})$ and it was calculated numerically by empirical data.

The following equation links the values of $\mathrm{c}$ and $\mathrm{P}$, directly on the basis of their definition (see Appendix, 2):

$$
\mathrm{c}=1-2 P(1-P) \text {. }
$$

The values of $\mathrm{c}$ were estimated for each specimen and then for each karyotype, using pooled data. The values of $95 \%$ confidence intervals around $\mathrm{c}$ values were calculated as $\mathrm{c} \pm 1.96 \mathrm{SE}$

\section{Evolutionary effects of cosegregation}

Evolutionary effects were evaluated for two hypothetic populations differing for two alternative forms of two chromosomal rearrangements, using an asymmetric two-population model. In this model one population is infinitely larger than the other (a so called "continent-island" model). The larger population is initially monomorphic for the standard karyotype and the small one is initially monomorphic for two Rb metacentrics. The continentisland model is particularly suitable to study early stages of speciation, when small, marginal populations are genetically diverging from the main, central population. It is assumed that cosegregation also involves the female germ line to the same extent and that the cosegregation values found in germ cells remain the same also in the progeny.

Computer deterministic simulations were performed to test whether cosegregation affects the stability of a chromosomal race, measured as the value of the critical migration rate $\left(\mathrm{m}_{\mathrm{c}}\right)$ over which the metacentric chromosomes are lost in the small population (Spirito et al., 1991). The values of $\mathrm{m}_{\mathrm{c}}$ were found for different values of the nondisjunction rate per trivalent (s) as an approximation to the coefficient of selection against heterozygotes for a chromosomal rearrangement - in the presence of random segregation $(P=$ $0.50, \mathrm{c}=0.50$ ) or of different levels of cosegregation.

An approximated equation was used to test whether cosegregation of two Robertsonian rearrangements affects the gene flow for biallelic, neutral genes. These genes may have different recombination rates with either centromere, which is the rearrangement site. The reduction in gene flow is measured as the equivalence of a migration rate reduction (Spirito et al., 1987); it is expressed as follows, taking into account cosegregation:

$$
\operatorname{MRE}=\frac{(1-s)^{2} r}{1-c(1-s)^{2}(1-r)}\left(\frac{(1-s)(1-c)(1-r)}{1-(1-s)(1-r)}+\frac{0.5(1-s)(1-c)}{1-0.5(1-s)}+c\right)
$$

where $\mathrm{MRE}=$ migration reduction equivalent; $\mathrm{s}=$ nondisjunction rate per trivalent (assumed to be the same for both trivalents), as an approximation to the coefficient of selection against heterozygotes; $r=$ recombination rate between the neutral locus and the centromere; $\mathrm{c}=$ cosegregation coefficient; this equation may be used for very low migration rates so gene flow in the presence of cosegregation can be compared to the case of random segregation. 
Table 1a. Frequencies of metaphases II with a different number of $\mathrm{Rb}$ metacentric chromosomes, among euploid (20 chromosome arms) and hyperploid aneuploid cells $(21-22$ chromosome arms) in double heterozygous mice.

\begin{tabular}{llrrr}
\hline \multirow{2}{*}{ Specimen } & \multirow{2}{*}{$\begin{array}{l}\text { Arm number/ } \\
\text { metaphase II }\end{array}$} & \multicolumn{2}{c}{$\begin{array}{c}\text { Number of Rb metacentric } \\
\text { chromosomes }\end{array}$} \\
\cline { 3 - 5 } & & 0 & 1 & 2 \\
\hline A & 20 & 14 & 20 & 16 \\
& 21 & 0 & 6 & 2 \\
B & 20 & 15 & 22 & 13 \\
& 21 & 0 & 2 & 1 \\
C & 20 & 14 & 20 & 16 \\
& 21 & 0 & 1 & 3 \\
D & 20 & 13 & 20 & 17 \\
& 21 & 0 & 7 & 5 \\
E & 20 & 18 & 15 & 17 \\
& 21 & 0 & 4 & 4 \\
F & 20 & 14 & 22 & 14 \\
& 21 & 0 & 3 & 5
\end{tabular}

\section{Results}

\section{Cosegregation}

The frequencies of metaphases II with a different number of $\mathrm{Rb}$ metacentric chromosomes, among euploid (20 chromosome arms) and aneuploid hyperploid cells (21-22 chromosome arms) for double, triple and quadruple heterozygotes are given in Tables $1 \mathrm{a}, \mathrm{b}, \mathrm{c}$.

The frequencies of different segregation patterns for double, triple and quadruple heterozygotes are given in Tables $2 \mathrm{a}, \mathrm{b}, \mathrm{c}$. Observed frequencies are significantly different compared to the expected ones following the hypothesis of random segregation of $\mathrm{Rb}$ metacentrics for all the karyotypes, on the basis of pooled data. The same results were found for many single specimens.

The observed values of the cosegregation coefficient (c) are similar among different karyotypes, on the basis of pooled data and are significantly higher than the value expected following the hypothesis of random segregation, i.e. $c=0.5$. This value lies always outside the $95 \%$ confidence interval of the observed $\mathrm{c}$ values. The $\mathrm{c}$ values found for single specimens were similar among them and to those found for pooled data for each karyotype (see Tables $2 \mathrm{a}, \mathrm{b}, \mathrm{c}$ ); in many cases the value $\mathrm{c}=0.5$ is outside the $95 \%$ confidence interval of the observed c values (in one specimen among six double heterozygotes, in two among four triple heterozygotes, and in all three quadruple heterozygotes).

These data support the hypothesis that "isomorphic" chromosomes tend to cosegregate; the value of cosegregation coefficient seems to be independent of the number and the parental origin of $\mathrm{Rb}$ metacentric chromosomes.

\section{Evolutionary effects}

The results of simulations to test the effects of cosegregation on the stability of the population with two $\mathrm{Rb}$ metacentrics are given in Table 3. Cosegregation of two $\mathrm{Rb}$ chromosomes helps
Table 1c. Frequencies of metaphases II with a different number of $\mathrm{Rb}$ metacentric chromosomes, among euploid (20 chromosome arms) and hyperploid aneuploid cells $(21-22$ chromosome arms) in quadruple heterozygous mice.

\begin{tabular}{llrrrrr}
\hline \multirow{2}{*}{ Specimen } & \multirow{2}{*}{$\begin{array}{l}\text { Arm number/ } \\
\text { metaphase II }\end{array}$} & \multicolumn{3}{c}{$\begin{array}{l}\text { Number of Rb metacentric } \\
\text { chromosomes }\end{array}$} \\
\cline { 3 - 7 } & & 0 & 1 & 2 & 3 & 4 \\
\hline $\mathrm{K}$ & 20 & 8 & 10 & 11 & 13 & 8 \\
& 21 & 0 & 2 & 2 & 3 & 2 \\
& 22 & 0 & 0 & 0 & 0 & 1 \\
$\mathrm{~L}$ & 20 & 10 & 11 & 16 & 9 & 4 \\
& 21 & 1 & 2 & 3 & 2 & 4 \\
& 22 & 0 & 0 & 1 & 0 & 0 \\
$\mathrm{M}$ & 20 & 8 & 12 & 10 & 15 & 5 \\
& 21 & 1 & 1 & 4 & 6 & 3 \\
& 22 & 0 & 0 & 0 & 2 & 0 \\
\hline
\end{tabular}

them to persist in small populations. The values found in the present work for cosegregation have a non-negligible and positive effect on the stabilization of the chromosomal races, due to linkage disequilibrium. This effect becomes very strong for very high values of the cosegregation coefficient.

The effects of cosegregation on the gene flow between a population with two $\mathrm{Rb}$ metacentrics and a population with the standard karyotype are given in Table 4 . For the values of $c$ found in the present work, the effect of cosegregation on gene flow of other neutral alleles is weak. However for each $\mathrm{s}(\mathrm{s}<0.5)$ there is a critical value of the recombination rate between the neutral gene and the centromere, $r_{c}$, over which cosegregation increases gene flow and under which cosegregation reduces it (Fig. 2).

\section{Discussion}

The aim of the present paper was to verify whether cosegregation instead of random segregation of isomorphic chromosomes takes place in mice heterozygous for several $\mathrm{Rb}$ metacentric chromosomes during meiosis I. Cosegregation was measured by the probability to reach the same pole for any pair of $\mathrm{Rb}$ chromosome.

The use and good efficiency of telomeric probes, and the clear, bright staining of centromeres with DAPI, allowed us to distinguish acrocentric and $\mathrm{Rb}$ metacentric chromosomes unambiguously (see Fig. 1c and d). As a result, cosegregation coefficients could be measured and were found to be significantly different from 0.5 (i.e. the expected value with random segregation) in pooled data and were independent of the number of $\mathrm{Rb}$ metacentrics involved. Data based on single specimens supported conclusions drawn on pooled data: all specimens showed c values higher than 0.5 (random segregation value) and similar among them; in many cases a 0.05 significance was reached. 
Table 2a. Frequencies of the segregation patterns in meiosis I of mice heterozygous for two Robertsonian metacentric chromosomes: a comparison between observed frequencies in euploid plus hyperploid spermatocytes II and the expected frequencies following the hypothesis of random segregation and estimates of cosegregation coefficients (c). The value of $\chi^{2}$ obtained for the homogeneity test among the different specimens is given in the last row under "pooled data".

Table 2b. Frequencies of the segregation patterns in meiosis I of mice heterozygous for three Robertsonian metacentric chromosomes: a comparison between observed frequencies in euploid plus hyperploid spermatocytes II and the expected frequencies following the hypothesis of random segregation and estimates of cosegregation coefficients (c). The value of $\chi^{2}$ obtained for the homogeneity test among the different specimens is given in the last row under "pooled data".

Table 2c. Frequencies of the segregation patterns in meiosis I of mice heterozygous for four Robertsonian metacentric chromosomes: a comparison between observed frequencies in euploid plus hyperploid spermatocytes II and the expected frequencies following the hypothesis of random segregation and estimates of cosegregation coefficients (c). The value of $\chi^{2}$ obtained for the homogeneity test among the different specimens is given in the last row under "pooled data".

\begin{tabular}{|c|c|c|c|c|c|c|}
\hline Specimen & $\begin{array}{l}\text { Segregation } \\
\text { pattern }\end{array}$ & $\begin{array}{l}\text { Expected } \\
\text { frequencies }\end{array}$ & $\begin{array}{l}\text { Observed } \\
\text { frequencies }\end{array}$ & $\chi^{2}$ & $\mathrm{c}$ & $\begin{array}{l}95 \% \text { confidence } \\
\text { interval }\end{array}$ \\
\hline A & $\begin{array}{l}2,0 \\
1,1\end{array}$ & $\begin{array}{l}29 \\
29\end{array}$ & $\begin{array}{l}32 \\
26\end{array}$ & 0.431 & 0.552 & $0.424-0.680$ \\
\hline B & $\begin{array}{l}2,0 \\
1,1\end{array}$ & $\begin{array}{l}26.5 \\
26.5\end{array}$ & $\begin{array}{l}29 \\
24\end{array}$ & 0.302 & 0.547 & $0.413-0.681$ \\
\hline $\mathrm{C}$ & $\begin{array}{l}2,0 \\
1,1\end{array}$ & $\begin{array}{l}27 \\
27\end{array}$ & $\begin{array}{l}33 \\
21\end{array}$ & 2.241 & 0.611 & $0.481-0.741$ \\
\hline D & $\begin{array}{l}2,0 \\
1,1\end{array}$ & $\begin{array}{l}31 \\
31\end{array}$ & $\begin{array}{l}35 \\
27\end{array}$ & 0.790 & 0.565 & $0.441-0.688$ \\
\hline E & $\begin{array}{l}2,0 \\
1,1\end{array}$ & $\begin{array}{l}29 \\
29\end{array}$ & $\begin{array}{l}39 \\
19\end{array}$ & $6.224^{\mathrm{a}}$ & 0.672 & $0.552-0.793$ \\
\hline $\mathrm{F}$ & $\begin{array}{l}2,0 \\
1,1\end{array}$ & $\begin{array}{l}29 \\
29\end{array}$ & $\begin{array}{l}33 \\
25\end{array}$ & 0.845 & 0.569 & $0.442-0.696$ \\
\hline Pooled data & $\begin{array}{l}2,0 \\
1,1\end{array}$ & $\begin{array}{l}171.5 \\
171.5\end{array}$ & $\begin{array}{l}201 \\
142\end{array}$ & $\begin{array}{l}9.808^{\mathrm{b}} \\
2.723^{\mathrm{c}}\end{array}$ & 0.586 & $0.534-0.638$ \\
\hline $\begin{array}{ll}\mathrm{a} & p<0.05 \\
\mathrm{~b} & p<0.01 \\
\mathrm{c} & p=0.7426\end{array}$ & & & & & & \\
\hline
\end{tabular}

\begin{tabular}{|c|c|c|c|c|c|c|}
\hline Specimen & $\begin{array}{l}\text { Segregation } \\
\text { pattern }\end{array}$ & $\begin{array}{l}\text { Expected } \\
\text { frequencies }\end{array}$ & $\begin{array}{l}\text { Observed } \\
\text { frequencies }\end{array}$ & $\chi^{2}$ & $\mathrm{c}$ & $\begin{array}{l}95 \% \text { confidence } \\
\text { interval }\end{array}$ \\
\hline G & $\begin{array}{l}3,0 \\
2,1\end{array}$ & $\begin{array}{l}15 \\
45\end{array}$ & $\begin{array}{l}20 \\
40\end{array}$ & 1.800 & 0.556 & $0.476-0.635$ \\
\hline $\mathrm{H}$ & $\begin{array}{l}3,0 \\
2,1\end{array}$ & $\begin{array}{l}16 \\
48\end{array}$ & $\begin{array}{l}25 \\
39\end{array}$ & $6.224^{\mathrm{a}}$ & 0.594 & $0.514-0.673$ \\
\hline I & $\begin{array}{l}3,0 \\
2,1\end{array}$ & $\begin{array}{l}14.25 \\
42.75\end{array}$ & $\begin{array}{l}16 \\
41\end{array}$ & 0.146 & 0.520 & $0.443-0.598$ \\
\hline $\mathrm{J}$ & $\begin{array}{l}3,0 \\
2,1\end{array}$ & $\begin{array}{l}15.5 \\
46.5\end{array}$ & $\begin{array}{l}23 \\
39\end{array}$ & $4.215^{\mathrm{a}}$ & 0.581 & $0.500-0.661$ \\
\hline Pooled data & $\begin{array}{l}3,0 \\
2,1\end{array}$ & $\begin{array}{r}60.75 \\
182.25\end{array}$ & $\begin{array}{c}84 \\
159\end{array}$ & $\begin{array}{l}11.360^{\mathrm{b}} \\
1.701^{\mathrm{c}}\end{array}$ & 0.564 & $0.524-0.604$ \\
\hline $\begin{array}{ll}\text { a } & p<0.05 . \\
\text { b } & p<0.001 . \\
\text { c } & p=0.6367 .\end{array}$ & & & & & & \\
\hline
\end{tabular}

\begin{tabular}{|c|c|c|c|c|c|c|}
\hline Specimen & $\begin{array}{l}\text { Segregation } \\
\text { pattern }\end{array}$ & $\begin{array}{l}\text { Expected } \\
\text { frequencies }\end{array}$ & $\begin{array}{l}\text { Observed } \\
\text { frequencies }\end{array}$ & $\chi^{2}$ & $\mathrm{c}$ & $\begin{array}{l}95 \% \text { confidence } \\
\text { interval }\end{array}$ \\
\hline K & $\begin{array}{l}4,0 \\
3,1 \\
2,2\end{array}$ & $\begin{array}{l}7.5 \\
30 \\
22.5\end{array}$ & $\begin{array}{l}19 \\
28 \\
13\end{array}$ & $21.778^{\mathrm{a}}$ & 0.622 & $0.556-0.687$ \\
\hline $\mathrm{L}$ & $\begin{array}{l}4,0 \\
3,1 \\
2,2\end{array}$ & $\begin{array}{l}7.875 \\
31.5 \\
23.625\end{array}$ & $\begin{array}{l}19 \\
24 \\
20\end{array}$ & $18.058^{\mathrm{a}}$ & 0.589 & $0.529-0.649$ \\
\hline M & $\begin{array}{l}4,0 \\
3,1 \\
2,2\end{array}$ & $\begin{array}{l}8.375 \\
33.5 \\
25.125\end{array}$ & $\begin{array}{l}17 \\
36 \\
14\end{array}$ & $13.995^{\mathrm{a}}$ & 0.597 & $0.535-0.659$ \\
\hline Pooled data & $\begin{array}{l}4,0 \\
3,1 \\
2,2\end{array}$ & $\begin{array}{l}23.75 \\
95 \\
71.25\end{array}$ & $\begin{array}{l}55 \\
88 \\
47\end{array}$ & $\begin{array}{l}49.890^{\mathrm{a}} \\
4.077^{\mathrm{b}}\end{array}$ & 0.602 & $0.566-0.638$ \\
\hline $\begin{array}{ll}\text { a } & p<0.001 . \\
\text { b } & p=0.3957\end{array}$ & & & & & & \\
\hline
\end{tabular}




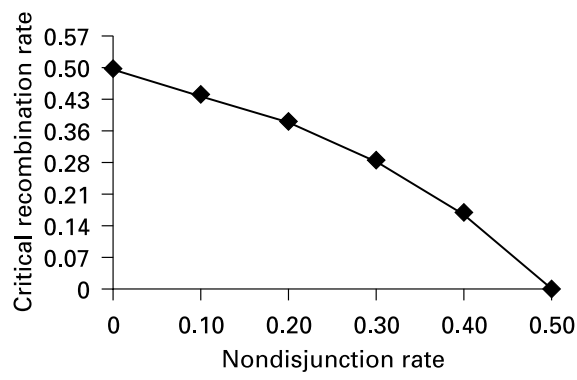

Fig. 2. Critical values of the recombination frequency $\left(r_{c}\right)$ between a neutral gene and the centromere (the region involved in the rearrangement in a $\mathrm{Rb}$ metacentric chromosome), below which cosegregation leads to an increase of the barrier to gene flow, as a function of the nondisjunction rate of the involved trivalent: $r_{c}=(1 / 2-s) /(1-s)$.

Table 3. Critical value of the migration rate $\left(\mathrm{m}_{\mathrm{c}}\right)$ below which two $\mathrm{Rb}$ metacentric chromosomes are maintained in a hypothetical island population, following a continent-island model. The values of $\mathrm{mc}$ are shown for each value of the coefficient of selection (s) against heterozygotes for a single chromosomal rearrangement, in the presence of random segregation $(P=$ $0.50, \mathrm{c}=0.50)$ or of different levels of cosegregation until total cosegregation $(P=1, \mathrm{c}=1)$

\begin{tabular}{llllll}
\hline$P^{\mathrm{a}}$ & $\mathrm{c}^{\mathrm{b}}$ & \multicolumn{3}{l}{$\mathrm{s}$} & \\
\cline { 3 - 6 } & & 0.05 & 0.1 & 0.2 & 0.3 \\
\hline 0.5 & 0.5 & 0.006 & 0.012 & 0.027 & 0.043 \\
0.6 & 0.52 & 0.006 & 0.013 & 0.027 & 0.043 \\
0.7 & 0.58 & 0.006 & 0.013 & 0.028 & 0.044 \\
0.8 & 0.68 & 0.007 & 0.014 & 0.030 & 0.047 \\
0.9 & 0.82 & 0.008 & 0.016 & 0.033 & 0.051 \\
1 & 1 & 0.012 & 0.023 & 0.043 & 0.059 \\
\hline
\end{tabular}

$P$ is the probability to migrate to the "preferential" pole for each Rb metacentric $\mathrm{c}$ represents the coefficient of cosegregation for two Rb metacentrics.

Table 4. Efficiency of the barrier against gene flow for a neutral gene in the presence of different values of selection against single heterozygotes $(\mathrm{s})$ and of recombination rate $(r)$ between that gene and one of the rearrangements. Values of MRE (migration reduction equivalence) are shown for each pair of the values, in presence of random segregation $(P=0.5, \mathrm{c}=0.5)$ and of two alternative levels of cosegregation.

\begin{tabular}{lllllll}
\hline \multirow{2}{*}{$\mathrm{s}$} & $P^{\mathrm{a}}$ & $\mathrm{c}^{\mathrm{b}}$ & $\mathrm{r}$ & & \\
\cline { 3 - 6 } & & & 0.5 & 0.1 & 0.02 & 0.004 \\
\hline 0.01 & 0.5 & 0.5 & 0.96079 & 0.89027 & 0.65127 & 0.27805 \\
& 0.75 & 0.63 & 0.96082 & 0.88639 & 0.64744 & 0.27632 \\
& 1 & 1 & 0.96098 & 0.83123 & 0.49623 & 0.16458 \\
0.1 & 0.5 & 0.5 & 0.66942 & 0.38756 & 0.12481 & 0.02843 \\
& 0.75 & 0.63 & 0.67166 & 0.37652 & 0.12008 & 0.02729 \\
& 1 & 1 & 0.68067 & 0.29889 & 0.07856 & 0.01677 \\
0.3 & 0.5 & 0.5 & 0.28994 & 0.10187 & 0.02401 & 0.00498 \\
& 0.75 & 0.63 & 0.29764 & 0.09913 & 0.02305 & 0.00477 \\
& 1 & 1 & 0.32450 & 0.08766 & 0.01885 & 0.00383 \\
0.5 & 0.5 & 0.5 & 0.11111 & 0.03030 & 0.00654 & 0.00133 \\
& 0.75 & 0.63 & 0.11864 & 0.03074 & 0.00656 & 0.00133 \\
& 1 & 1 & 0.14286 & 0.03226 & 0.00662 & 0.00133 \\
\hline
\end{tabular}

$P$ is the probability to migrate to the "preferential" pole for each $\mathrm{Rb}$ metacentric. $\mathrm{c}$ is the coefficient of cosegregation for two Rb metacentrics.
The experimental scheme allowed us to analyse the contribution of specific $\mathrm{Rb}$ metacentrics to cosegregation in a similar genetic background. The chromosomes $\mathrm{Rb}(1.3) 1 \mathrm{Bnr}$ and $\mathrm{Rb}(9.14) 6 \mathrm{Bnr}$ were involved in double heterozygotes; the chromosome $\mathrm{Rb}(4.6) 2 \mathrm{Bnr}$ was involved, besides the former two, in triple heterozygotes; the chromosome $\mathrm{Rb}(16.17) 7 \mathrm{Bnr}$ was involved, besides the former three, in quadruple heterozygotes. The addition of single $\mathrm{Rb}$ chromosomes did not change the cosegregation coefficients significantly; this result suggests that cosegregation is due to chromosome shape (metacentric or acrocentric) rather than to specific composition of $\mathrm{Rb}$ metacentrics.

This approach is possible only in mice with a reconstructed karyotype; however, only the analysis of heterozygous specimens caught in hybrid zones could allow an estimate of cosegregation in nature and an evaluation on its effective role in cladogenesis. Another alteration of meiotic segregation, that is nondisjunction, was found to reach higher rates in heterozygotes obtained by laboratory crosses than in natural hybrids (for a review, see Searle, 1993).

Previous reports were mainly based upon karyotype analysis of backcross progeny from males heterozygous for several $\mathrm{Rb}$ metacentric chromosomes (White et al., 1978; Said et al., 1993; Lenormand et al., 1997). This approach gives a contribution to the understanding of evolutionary effects of cosegregation; however, complex selective patterns may take place before birth (Lenormand et al., 1997). Therefore it is necessary to investigate the immediate meiosis II products to verify whether cosegregation takes place. Present data are in agreement with some estimates of cosegregation in multiple heterozygous male mice (Rizzoni and Spirito, 1999).

There is a small but positive effect of cosegregation on the stabilization of new chromosomal races (in the house mouse the Robertsonian races) for the cosegregation coefficient values experimentally found in the present work. "Reciprocal protection" among Rb metacentric chromosomes (Spirito et al., 1991) increases and the small population can tolerate a higher migration rate, compared to the case of random segregation, without losing its $\mathrm{Rb}$ chromosomes. Two cosegregating Rb metacentrics "protect" each other with more efficiency than two randomly segregating ones do.

This result suggests that cosegregation contributes to the persistence of newly arisen chromosomal rearrangements, therefore maintaining the karyotypic difference between parapatric chromosomal races and the chromosomal clines coincident between the two races (see Searle, 1993).

For the values experimentally found in the present work, there is a weak effect of cosegregation on the reduction of the flow of a "neutral" gene due to the underdominant rearrangement. Gene flow is more reduced in the presence of cosegregation, than it is in the absence of cosegregation only for genes linked to the centromere of the $\mathrm{Rb}$ chromosome. On the contrary gene flow is less reduced in the presence of cosegregation, than it is in the absence of cosegregation, for unlinked genes. That is, cosegregation weakens the efficiency of underdominant rearrangements as a barrier to gene flow, even if to a small extent, for the majority of the genome, following our model. 


\section{Appendix}

$1 a$

$\mathrm{Rb} 1, \mathrm{Rb} 2$ and $\mathrm{Rb} 3$ are three $\mathrm{Rb}$ metacentric chromosomes. The probability that $\mathrm{Rb} 1$ and $\mathrm{Rb} 2$ reach the opposite poles is $(1-\mathrm{c})$; when this segregation occurs, the probability that $\mathrm{Rb} 3$ reaches the same pole as $\mathrm{Rb} 2$ is $1 / 2$; the probability that $\mathrm{Rb} 1$ reaches one pole and $\mathrm{Rb} 2$, and $\mathrm{Rb} 3$ reach the other pole is, therefore, $1 / 2(1-c)$. This is one of the three combinations which show a segregation pattern $(2,1)$; the other two combinations involve $\mathrm{Rb} 2$ and $\mathrm{Rb} 3$, as the $\mathrm{Rb}$ chromosome which "lonely" reaches one pole. Therefore the expected frequency of a $(2,1)$ segregation pattern is $3 / 2(1-c)$. Obviously, being $\mathrm{f}(3,0)=1-\mathrm{f}(2,1)$, then, by simple computations, $f(3,0)=1-3 / 2(1-\mathrm{c})$. Therefore, using the maximum likelihood method, the logarithm of the likelihood function is the following:

$\log (\mathrm{L})=\mathrm{F}(3,0) \log (1-3 / 2(1-\mathrm{c}))+\mathrm{F}(2,1) \log 3 / 2(1-\mathrm{c})$

the value of $c$ which gives the highest value of $\log (\mathrm{L})$ is $\mathrm{f}(3,0)+\mathrm{f}(2,1) / 3$

$1 b$

$\mathrm{Rb} 1, \mathrm{Rb} 2, \mathrm{Rb} 3$ and $\mathrm{Rb} 4$ are four $\mathrm{Rb}$ metacentric chromosomes The probability that $\mathrm{Rb} 1$ and $\mathrm{Rb} 2$ reach the opposite poles is $(1-\mathrm{c})$; starting from this condition, the probability that $\mathrm{Rb} 3$ and $\mathrm{Rb} 4$ reach the same pole is $\mathrm{c}$. Hence the probability that they reach the same pole as Rb2 is $1 / 2$; the probability that $\mathrm{Rb} 1$ reaches one pole and $\mathrm{Rb} 2, \mathrm{Rb} 3$ and $\mathrm{Rb} 4$ reach the other pole is, therefore, $1 / 2 c(1-c)$. This is one of the four combinations which show a segregation pattern $(3,1)$; the other three combinations involve $\mathrm{Rb} 2, \mathrm{Rb} 3$ and $\mathrm{Rb} 4$, as the $\mathrm{Rb}$ chromosome which "lonely" reaches one pole. Therefore the expected frequency of a $(3,1)$ segregation pattern is $2 c(1-c)$.
If $\mathrm{Rb} 1$ reaches one pole, the probability that $\mathrm{Rb} 2$ reach the other pole is $(1-\mathrm{c})$; the probability that $\mathrm{Rb} 3$ and $\mathrm{Rb} 4$ reach the opposite poles is $(1-\mathrm{c})$; starting from this condition, the probability that $\mathrm{Rb} 3$ reaches the same pole as $\mathrm{Rb} 1$, and, as a consequence, $\mathrm{Rb} 4$ reaches the same pole as $\mathrm{Rb} 2$ is $1 / 2(1-\mathrm{c})^{2}$. This is one of the three combinations which show a segregation pattern $(2,2)$; the other two combinations involve $\mathrm{Rb} 2$ and $\mathrm{Rb} 4$, as the $\mathrm{Rb}$ chromosome which reaches the same pole as $\mathrm{Rb} 1$. Therefore the expected frequency of a $(2,2)$ segregation pattern is $3 / 2(1-c)^{2}$.

Obviously, being $\mathrm{f}(4,0)=1-(\mathrm{f}(2,2)+\mathrm{f}(3,1))$, then, by simple computations, $f(4,0)=1 / 2 c^{2}+c-1 / 2$.

Therefore, using the maximum likelihood method, the logarithm of the likelihood function is the following:

$$
\begin{aligned}
\log (L)= & F(4,0) \log \left(1 / 2 c^{2}+c-1 / 2\right)+F(3,1) \log \left(2 c-2 c^{2}\right) \\
& +F(2,2) \log \left(3 / 2 c^{2}-3 c+3 / 2\right)
\end{aligned}
$$

$\mathrm{Rb} 1$ and $\mathrm{Rb} 2$ are two $\mathrm{Rb}$ metacentric chromosomes; if $P$ is the probability to reach the favourite pole for each of them, the probability that both reach the same pole, i.e. the cosegregation coefficient $\mathrm{c}$, is the sum of the probabilities that both reach the favourite pole, $P^{2}$, and that both reach the other pole, $(1-P)^{2} ;$ from $\mathrm{c}=P^{2}+(1-P)^{2}$ it can be easily obtained $\mathrm{c}=1-2 P(1-P)$

\section{Acknowledgements}

Drs. Laura Stronati's and M. Giuseppa Grollino's (ENEA Section of Toxicology and Biomedical Sciences) expert advice on the application of FISH techniques is gratefully acknowledged.

\section{References}

Barton NH: Gene flow past a cline. Heredity 43:333339 (1979).

Barton NH: Multilocus clines. Evolution 37:454-471 (1983).

Barton NH, Bengtsson BO: The barrier to genetic exchange between hybridising populations. Heredity 56:357-376 (1986).

Castiglia R, Capanna E: Contact zone between chromosomal races of Mus musculus domesticus. 2. Fertility and segregation in laboratory-reared and wild mice heterozygous for multiple Robertsonian rearrangements. Heredity 85:147-156 (2000).

Evans EP, Breckon G, Ford CE: An air-drying method for meiotic preparations from mammalian testes. Cytogenetics 3:289-294 (1964).

Hauffe HC, Searle JB: Chromosomal heterozygosity and fertility in house mice (Mus musculus domesticus) from northern Italy. Genetics 150:1143-1154 (1998).

Hedrick PW: The establishment of chromosomal variants. Evolution 35:322-332 (1981).

Lande R: Effective deme sizes during long-term evolution estimated from rates of chromosomal rearrangements. Evolution 33:234-251 (1979).
Lande R: The expected fixation rate of chromosomal inversions. Evolution 38:743-752 (1984).

Lenormand T, Fel-Clair F, Manolakou K, Alibert P, Britton-Davidian J: Chromosomal transmission bias in laboratory hybrids between wild-strains of the two European subspecies of house mice. Genetics 147:1279-1287 (1997).

Rizzoni M, Spirito F: Nonrandom segregation in multiple Robertsonian heterozygotes in the house mouse (Mus musculus domesticus): analysis of metaphases of spermatocytes II of mice from a hybrid zone between a Robertsonian population and a population with the standard karyotype. Ital J Zool 66:23-25 (1999).

Said K, Saad A, Auffray JC, Britton-Davidian J: Fertility estimates in the Tunisian all-acrocentric and Robertsonian populations of the house mouse and their chromosomal hybrids. Heredity 71:532-538 (1993).
Searle JB: Chromosomal hybrid zones in eutherian mammals, in Harrison RG (ed): Hybrid Zones and Evolutionary Process, pp 309-352 (Oxford University Press, New York 1993)

Spirito F, Rizzoni M, Lolli E, Rossi C: Reduction of neutral gene flow due to the partial sterility of heterozygotes for a linked chromosome mutation. Theoret Pop Biol 31:323-338 (1987).

Spirito F, Rossi C, Rizzoni M: Populational interactions among underdominant chromosome rearrangements help them to persist in small demes. J Evol Biol 3:501-512 (1991).

Walsh JB: Rate of accumulation of reproductive isolation by chromosome rearrangements. Am Nat 120:510-532 (1982).

White BJ, Crandall C, Raveché ES, Tjio JH: Laboratory mice carrying three pairs of Robertsonian translocations: establishment of a strain and analysis of meiotic segregation. Cytogenet Cell Genet 21:113138 (1978).

White MJD: Models of speciation. Science 159:10651070 (1968).

White MJD: Chain processes in chromosomal speciation. Syst Zool 27:285-298 (1978). 